\title{
Molecular Analysis of The Rs1800629 Polymorphic Variant in the TNF-Gene in The Pathogenesis of Fetal Loss Syndrome
}

\author{
N N Mavlyanova ${ }^{1 *}$ and K T Boboev ${ }^{2}$ \\ ${ }^{1}$ Republican Specialized Scientific and Practical Medical Center for Obstetrics and Gynecology at the Ministry of Public Health of the Republic of Uzbekistan \\ ${ }^{2}$ Republican Specialized Scientific and Practical Medical Center for Hematology at the Ministry of Public Health of the Republic of Uzbekistan \\ *Corresponding author: N N Mavlyanova, Republican Specialized Scientific and Practical Medical Center for Obstetrics and Gynecolo- \\ gy at the Ministry of Public Health of the Republic of Uzbekistan.
}

To Cite This Article: N N Mavlyanova, K T Boboev, Molecular Analysis of The Rs1800629 Polymorphic Variant in the TNF-Gene in The Pathogenesis of Fetal Loss Syndrome. 2020 - 10(4). AJBSR.MS.ID.001536. DOI: 10.34297/AJBSR.2020.10.001536.

Received: 眥 September 28, 2020; Published: 眥 October 13, 2020

\begin{abstract}
This paper presents molecular genetic research of the TNF- $\alpha$ gene polymorphism in pregnant women with fetal loss syndrome. Analysis of molecular genetic research showed that allele A and heterozygous genotypes of the rs1800629 polymorphism in the TNF- $\alpha$ gene may be markers of a tendency for an increased risk of developing fetal loss syndrome in Uzbekistan. There is a tendency towards an increase in the frequency of the unfavorable allele A of the TNF- $\alpha$ gene in female patients with a severe form of Fetal Loss Syndrome (FLS) as compared with its mild case [1,2].

Keywords: Fetal Loss Syndrome, rs1800629 polymorphism, TNF- $\alpha$ gene, Genetics, Anemia, Heterozygous, High-Risk Pregnancy, Gynecology, Obstetrics, Biosubstances, Placentology, Cytotrophoblast
\end{abstract}

\section{Introduction}

The research priority in pathologies in obstetrics and gynecology is studying the state of formation of the 'mother-placenta-fetus' functional system, which ultimately is the birth of a healthy infant [3-5]. It is known that pregnancy is a developing system with a progressive load against the background of the influence of endoand exogenous factors, and certain deviations can be revealed in the repeat studies of the same indicators [4,8-10]. In doing so, an important role is given to the state of the placenta, which is a single biological system that unites these two organisms. Disorders of the functional and metabolic activity of the placenta, which exceed its compensatory and adaptive capabilities, ultimately contribute to the formation of a high-risk pregnancy. According to literature, the present stage in the development of placentology requires the study of finer biochemical mechanisms of regulation at the intraand intercellular level, which ensure the normal development of the placenta. The study of placental growth factors, which are powerful regulatory biosubstances that stimulate proliferative processes in the tissues of the placenta and fetus and are actively involved in angiogenesis, is of special interest $[1,2,7,13,14]$. Studies have demonstrated the role of the proinflammatory cytokine TNF- $\alpha$ in the regulation of apoptosis in the early stages of gestation, its participation in the regulation of the invasion of trophoblast cells is also known [7,16-18].

This factor enhances the proliferation of $\mathrm{T}$ and $\mathrm{B}$ cells, the formation of adhesive molecules, acute phase proteins, and activates fibroblasts. It is known that TGF- $\alpha$, a polypeptide that is a potent mitogen for epithelial cells and fibroblasts, is also involved in the growth and stimulation of follicle differentiation $[12,13]$. TGF- $\beta$ is a systemic cytokine since it and its specific receptors are found in almost all types of cells. TGF- $\beta$, isolated from homogenates of placental tissue, is recognized as a topical factor regulating the proliferation and invasion of cytotrophoblast in the placental-uterine region. Immunohistochemically, it is found in syncytitrophoblast, the epithelium of the villi, and extravillous 
cytotrophoblast subpopulations [12]. Despite the huge knowledge accumulated in the field of studying the biological functions of the cytokine TNF- $\alpha$ under normal and pathological conditions, intensive interdisciplinary studies of this phenomenon in the human body are still relevant. Currently, there is several reliable data on the role of the 308G>A (rs1800629) locus of the TNF- $\alpha$ gene in the pathogenesis and development of several diseases (Freidin M.B. et al., 2006). According to Sandford AJ et al. (2004), this polymorphism is reliably associated with cardiovascular diseases and atopic bronchial asthma. In this regard, the study of the distribution of rs1800629 polymorphism in the TNF- $\alpha$ gene in fetal loss syndrome is an urgent problem in obstetrics and gynecology.

\section{Objective of The Research}

To assess the significance of allelic and genotypic variants of the rs1800629 polymorphism in the TNF-gene in the formation of fetal loss syndrome in pregnant women living in Uzbekistan.

\section{Material and Methods of The Research}

In total, we examined 51 pregnant women aged 19 to 39 years, who were followed up on the basis of the clinic of the Republican Specialized Scientific and Practical Medical Center for Obstetrics and Gynecology at the Ministry of Public Health of the Republic of Uzbekistan. FLS was diagnosed on the basis of clinical laboratory and function (ultrasound) tests. Molecular genetic examination of biomaterials (DNA) was carried out on the basis of the Department of Molecular Medicine and Cell Technologies of the Republican Specialized Scientific and Practical Medical Center for Hematology at the Ministry of Public Health of the Republic of Uzbekistan. As a comparison group, a population control was used, which was represented by DNA samples $(n=80)$ of apparently healthy donors (not pregnant) from the DNA bank of the above department.

DNA samples were isolated from peripheral blood lymphocytes in accordance with the manufacturer's instructions (AmpliPrime RIBO-Prep (Next Bio LLC). The concentration and purity of the isolated DNA were assessed in measuring the optical density of DNA-containing solutions at 260 and $280 \mathrm{~nm}$ wavelength against TE on a NanoDrop 2000 spectrophotometer (USA). To detect polymorphism, a test kit of RPC Syntol (Russia) was used. The analysis of associations was conducted by comparing two samples on a case-control platform. Statistical analysis of the results was carried out using the statistical software package 'OpenEpi 2009, Version 2.3.'

\section{Results of The Research}

Among 51 pregnant women, Fetal Loss Syndrome (FLS) was diagnosed in 41 ones, which accounted for $80.4 \%$ of cases. Physiological carrying of pregnancy was noted in 10 patients, which accounted for $19.6 \%$ of cases. The diagnosis of Fetal Loss Syndrome (FLSD) was established on the basis of the degree of fetal growth retardation, the presence and severity of signs of chronic intrauterine fetal hypoxia, the degree of hemodynamic abnormalities in the mother-placenta-fetus system, the severity of impairments of the placenta hormonal function, and the effectiveness of the conducted therapy. To assess the clinical course of fetal loss syndrome, we used the working classification used in Fetal Growth Restriction Syndrome (FGRS). So, among 41 pregnant women with FGRS, taking into account the severity, Level I of severity was revealed in 14 patients, which was $34.1 \%$, Level II of severity was revealed in 21 patients (61.2\%), and Level III of severity was found in 6 patients, which was $14,6 \%$ of cases. To assess the detectability of allelic variants of rs1800629 of the TNF- $\alpha$ gene, molecular genetic blood testing was conducted (Table 1).

As it follows from Table 1, in the main group of patients, the frequency of functional allelic variants G and A was $90.2 \%$ and $19.6 \%$, respectively. In the control group, the distribution frequency of these alleles was $93.1 \%$ and $6.9 \%$, respectively. The calculated chance of detecting the pathological allele A was 1.5 $(\chi 2=0.8 ; P=0.495 \% 0.6017,3.603)$. The analysis of the detectability of the rs1800629 genotype polymorphism in the TNF- $\alpha$ gene in the studied group of pregnant women and control group showed that functional genotypes $\mathrm{G} / \mathrm{G}$ were determined in $80.4 \%$ against $86.2 \%$, respectively. Whereas heterozygous genotypes G/A in the control group were detected in $13.7 \%$ of cases, and in the group of pregnant women, they were revealed in $19.4 \%$, which was 1.4 times insignificantly higher than in non-pregnant patients $(\chi 2=0.8$; $\mathrm{P}=0.4 ; \mathrm{OR}=1.53$; 95\% 0.5979-3.915). It should be noted that the unfavorable genotype A/A was detected in neither group. The results of molecular genetic studies of the rs1800629 genotype polymorphism in the TNF- $\alpha$ gene were analyzed considering the detectability of fetal loss syndrome in pregnant women (Table 2).

Table 1: Frequency of distribution of alleles and genotypes of the rs1800629 polymorphism in the TNF- $\alpha$ gene in the group of pregnant women and the control group.

\begin{tabular}{|c|c|c|c|c|c|c|c|c|c|c|c|}
\hline \multirow{3}{*}{ \#\# } & \multirow{3}{*}{ Group } & \multicolumn{4}{|c|}{ Allele frequency } & \multicolumn{6}{|c|}{ Genotype distribution frequency } \\
\hline & & \multicolumn{2}{|c|}{ G } & \multicolumn{2}{|c|}{ A } & \multicolumn{2}{|c|}{ G/G } & \multicolumn{2}{|c|}{ G/A } & \multicolumn{2}{|c|}{$\mathbf{A} \backslash \mathbf{A}$} \\
\hline & & $\mathbf{n}^{*}$ & $\%$ & n* & $\%$ & $\mathbf{n}$ & $\%$ & $\mathbf{n}$ & $\%$ & $\mathbf{n}$ & $\%$ \\
\hline 1 & Main group $\mathrm{n}=51(102 *)$ & 92 & 90.2 & 10 & $19.6^{*}$ & 41 & 80.4 & 10 & 19.6 & 0 & 0 \\
\hline 2 & Control group $\mathrm{n}=80\left(160^{*}\right)$ & 149 & 93.1 & 11 & 6.9 & 69 & 86.2 & 11 & 13.7 & 0 & 0 \\
\hline
\end{tabular}

Note: $\mathrm{n}$ is the number of examined patients; * $\mathrm{n}$ is the number of studied chromosomes.

* is the index of reliability in relation to the indicators of the control group (without pregnancy) $\mathrm{P}<0.05$. 
Table 2: Parameters of the distribution of alleys and genotypes of the rs 1800629 polymorphism in the TNF- $\alpha$ gene in the groups of pregnant women with and without FLS

\begin{tabular}{|c|c|c|c|c|c|c|c|c|c|c|c|}
\hline \multirow{3}{*}{ \#\# } & \multirow{3}{*}{ Group } & \multicolumn{4}{|c|}{ Allele Frequency } & \multicolumn{6}{|c|}{ Genotype Distribution Frequency } \\
\hline & & \multicolumn{2}{|c|}{ G } & \multicolumn{2}{|r|}{ A } & \multicolumn{2}{|c|}{ G/G } & \multicolumn{2}{|c|}{ G/A } & \multicolumn{2}{|c|}{$\mathbf{A} \backslash \mathbf{A}$} \\
\hline & & $\mathbf{n}^{*}$ & $\%$ & $\mathbf{n}^{*}$ & $\%$ & $\mathbf{n}$ & $\%$ & $\mathbf{n}$ & $\%$ & $\mathbf{n}$ & $\%$ \\
\hline 1 & Main group of pregnant women with FLS $n=41\left(82^{*}\right)$ & 73 & 89.02 & 9 & $10.9 *$ & 32 & 78.05 & 9 & $21.9 *$ & 0 & 0 \\
\hline 2 & Healthy pregnant women without FLS $n=10(20)$ & 19 & 95 & 1 & 5 & 9 & 90 & 1 & 10 & 0 & 0 \\
\hline
\end{tabular}

Note: * -is the index of reliability in relation to the control group of pregnant women without FLS $(P<0.05)$

Table 3: Frequency of distribution of alleys and genotypes of the rs 1800629 polymorphism in the TNF- $\alpha$ gene in the groups of pregnant women with FLS, considering the severity of FGRS

\begin{tabular}{|c|c|c|c|c|c|c|c|c|c|c|c|}
\hline \multirow{3}{*}{ \#\# } & \multirow{3}{*}{ Group } & \multicolumn{4}{|c|}{ Allele Frequency } & \multicolumn{6}{|c|}{ Genotype Distribution Frequency } \\
\hline & & \multicolumn{2}{|c|}{ G } & \multicolumn{2}{|c|}{$\mathbf{A}$} & \multicolumn{2}{|c|}{$\mathbf{G} / \mathbf{G}$} & \multicolumn{2}{|c|}{ G/A } & \multicolumn{2}{|c|}{$\mathbf{A} \backslash \mathbf{A}$} \\
\hline & & $\mathbf{N}$ & $\%$ & $\mathbf{n}$ & $\%$ & $\mathbf{n}$ & $\%$ & $\mathbf{n}$ & $\%$ & $\mathbf{n}$ & $\%$ \\
\hline 1 & Pregnant women Level I severity of FGRS N=14(28) & 26 & 92.8 & 2 & 7.1 & 12 & 85.7 & 2 & 14.3 & 0 & 0 \\
\hline 2 & Level II severity of FGRS N=21(42) & 36 & 85.7 & 6 & $14.3^{*}$ & 15 & 71.4 & 6 & $28.6^{*}$ & 0 & 0 \\
\hline 3 & Level III severity of FGRS $n=6(12)$ & 11 & 91.6 & 1 & $8.3^{*}$ & 5 & 83.3 & 1 & 16.6 & 0 & 0 \\
\hline 4 & Healthy pregnant women $n=10(20)$ & 19 & 95 & 1 & 5 & 9 & 90 & 1 & 10 & 0 & 0 \\
\hline
\end{tabular}

Table 3: Expected and observed frequency of distribution of genotypes of the rs 1800629 polymorphism in the TNF-a gene in groups of pregnant women with FLS according to the Hardy-Weinberg principle.

\begin{tabular}{|c|c|c|c|c|}
\hline \multirow{2}{*}{ Genotypes } & \multicolumn{2}{|c|}{ Genotype Frequency } & \multirow{2}{*}{$\chi^{2}$} & \multirow{2}{*}{$\mathbf{P}$} \\
\hline & Expected & Observed & & \\
\hline $\mathrm{G} / \mathrm{G}$ & 0.78 & 0.79 & 0.008 & \multirow{4}{*}{0.43} \\
\hline $\mathrm{G} / \mathrm{A}$ & 0.22 & 0.19 & 0.122 & \\
\hline $\mathrm{A} / \mathrm{A}$ & 0 & 0.01 & 0.494 & \\
\hline Total & 1 & 1 & 0.623 & \\
\hline
\end{tabular}

The analysis of studies showed that in the group of pregnant women without FLS, the detectability of the unfavorable A allele of the TNF gene was $5.0 \%(1 / 10)$, while in pregnant women with FLS, it was $10.9 \%(9 / 41)$, which is 2.2 times insignificantly exceeded the indicators of healthy pregnant women $(\chi 2=0.6 ; \mathrm{P}=0.4 ; \mathrm{OR}=2.3$; $95 \% 0.2793-19.65)$. At the same time, there is a tendency to an increase in the unfavorable allele in the subgroup of patients without FLS. The detectability frequency of polymorphism of favorable $G / G$ genotypes in the examined groups of pregnant women was $78.05 \%$ and $90 \%$, respectively. While the polymorphism of heterozygous genotypes G/A in the group of patients with the physiological course of pregnancy was $10.0 \%(1 / 10)$, and in pregnant women with FLS, it was $21.9 \%$ (9/41), which was 2.5 times insignificantly higher than the indicators of pregnant women without FLS $(\chi 2=0.7$; $\mathrm{P}=0.4 ; \mathrm{OR}=2.53 ; 95 \% 0.2821-22.71$ ) (there is also a tendency to an increase in the unfavorable genotype in the first subgroup of patients). The homozygous unfavorable genotype A/A was detected in neither subgroup. The results of molecular genetic testing were analyzed considering the severity of FGRS. Thus, in pregnant women with Level I severity of FGRS, the polymorphism of heterozygous genotypes G/A was detected in $14.3 \%$ of cases, in pregnant women with Level II thereof, it was detected in $28.6 \%$ of cases, and in pregnant women with Level III thereof, it was detected in $16.6 \%$ of cases, respectively (Table 3).

As it follows from Table 4, the indices of the frequency of distribution of the G308A genotype polymorphism in the TNF- $\alpha$ gene in the main group of pregnant women with FLS according to the Hardy-Weinberg principle showed that the observed frequency of $\mathrm{G} / \mathrm{G}$ and $\mathrm{G} / \mathrm{A}$ genotypes was 0.78 and 0.22 , respectively, while the expected frequency of genotypes was 0.79 and 0.19 , respectively. The observed and expected frequencies of homozygous unfavorable A/A genotypes were $0.0 \%$ and $1.2 \%$ of cases $(P>0.05)$. In the group of pregnant women without FLS, the observed and expected frequencies of heterozygous G/A genotypes were found in 0.1 and 0.9 cases, and homozygous non-functional genotypes A/A were found in 0.0 and 0.025 , respectively $(\mathrm{P}>0.05)$ (Table 4). Thus, the study of the distribution of the rs1800629 genotypes in the TNF- $\alpha$ gene showed that for this locus, both in the group of patients with FLS and in the control group, the observed distribution of genotypes corresponds to the theoretically expected distribution according to the Hardy-Weinberg principle ( $p>0.05$ ). Clinical laboratory and functional studies of 51 pregnant women revealed concomitant somatic pathology in 20 women, which was $39.2 \%$ of cases. The largest number of comorbidities was found in the group of pregnant women with FLS, which was 95\% (19 out of 20). 
Table 4: Expected and observed frequencies of distribution of genotypes of the rs 1800629 polymorphism in the TNF- $\alpha$ gene in groups of pregnant women without FLS according to the Hardy-Weinberg principle.

\begin{tabular}{|c|c|c|c|c|}
\hline \multirow{2}{*}{ Genotypes } & \multicolumn{2}{|c|}{ Genotype Frequency } & \multirow{2}{*}{$\chi^{2}$} & \multirow{2}{*}{$\mathbf{P}$} \\
\hline & Observed & Expected & & \\
\hline $\mathrm{G} / \mathrm{G}$ & 0.9 & 0.9 & 0 & \multirow{4}{*}{0.86} \\
\hline $\mathrm{G} / \mathrm{A}$ & 0.1 & 0.09 & 0.003 & \\
\hline $\mathrm{A} / \mathrm{A}$ & 0 & 0.01 & 0.025 & \\
\hline Total & 1 & 1 & 0.028 & \\
\hline
\end{tabular}

Among them, diseases of the hemic system were revealed in 9 patients, which amounted to $47.4 \%$, those of the CVS and GUS were revealed in 4 pregnant women, which amounted to $21.05 \%$ of cases, respectively. Whilst, considering the polymorphism of the rs1800629 genotypes in the TNF- $\alpha$ gene, in the group of pregnant women with heterozygous genotypes $A / G$, comorbidity was revealed in 9 patients, which amounted to $90 \%$ of cases. Among the comorbidities, a pathology of the hemic system (severe anemia, thrombocytopenic purpura) was most often detected-in 6 patients out of 10 , which amounted to $60.0 \%$ of cases. A disease of the CVS was detected in 1 patient, a disease of the GUS was detected in 1 patient, and hepatitis was detected in 1 patient. In our opinion, the data obtained are of great importance to understand the pathogenesis of fetal loss syndrome. According to the literature, there are reliable data on the study of genetic predictors of the expression of tumor necrosis factor- $\alpha$ in the initiation and development of Chronic Heart Failure (CHF). It was found that the level of the pro-inflammatory cytokine TNF- $\alpha$ in the blood of patients with CHF is associated with a high risk of developing and functional class of the severity of CHF clinical manifestations.

Associative relationships were established between the level of TNF- $\alpha$ in the blood serum, as well as the TNF- $\alpha$ gene polymorphism, and a high risk of developing and severity of CHF. The analysis of the obtained results shows that the distribution of all genotypes of the rs 1800629 polymorphism in the TNF- $\alpha$ gene in the pregnant and control groups corresponds to the HardyWeinberg principle, indicating the absence of the influence of systematic or random factors that can change the genetic structure of populations. The study of the genetic structure of this marker revealed a tendency to an increase in the level of the unfavorable allele A and heterozygosity G/A in the group of pregnant women with fetal loss syndrome in relation to the control group-pregnant women without FLS (21.9\% and $10.0 \%$, respectively). Thus, allele A and heterozygous genotypes of the rs1800629 polymorphism in the TNF- $\alpha$ gene may be markers of the tendency for an increased risk of developing fetal loss syndrome in Uzbekistan. Here, it is necessary to note a tendency towards an increase in the frequency of the unfavorable A allele of the rs1800629 in the TNF- $\alpha$ gene in patients with a severe form of FLS as compared to its mild case. For the final determination of the role of this marker in the FLS formation and clinical course, we consider it expedient to conduct additional and in-depth studies.

\section{Conclusion}

1. Analysis of molecular genetic studies showed that allele A and heterozygous genotypes of the rs1800629 polymorphism in the TNF- $\alpha$ gene may be markers of a tendency for an increased risk of developing fetal loss syndrome in Uzbekistan.

2. There is a tendency towards an increase in the frequency of the unfavorable allele A of the rs1800629 in the TNF- $\alpha$ gene in patients with a severe form of FLS as compared to its mild case.

\section{References}

1. Melmed S (2017) Chapter 15 - Acromegaly. The Pituitary (Fourth Edition) pp. 423-466.

2. Colao A, Grasso LFS, Giustina A, Mel med S, Chanson P, et al. (2019) Acromegaly. Nat Rev Dis Primers 5(1): 20.

3. Dal J, Feldt Rasmussen U, Andersen M, Kristensen L, Laurberg P, et al. (2016) Acromegaly incidence, prevalence, complications and long-term prognosis: a nationwide cohort study. Eur J Endocrinol 175(3): 181-190.

4. Orphanet (2020) rare diseases. Acromegaly.

5. Agustsson, TT, Baldvinsdottir, Jonasson JG, Olafsdottir E, Steinthorsdottir $\mathrm{V}$, et al. (2015) The epidemiology of pituitary adenomas in Iceland, 1955-2012: a nationwide population-based study. Eur J Endocrinol 173(5): 655-664.

6. Gruppetta M, Mercieca C, Vassallo J (2013) Prevalence and incidence of pituitary adenomas: a population based study in Malta. Pituitary 16(4): 545-553.

7. Mestron A, Webb SM, Astorga R, Benito P, Catala M, et al. (2004) Epidemiology, clinical characteristics, outcome, morbidity and mortality in acromegaly based on the Spanish Acromegaly Registry (Registro Español de Acromegalia, REA). Eur J Endocrinol 151(4): 439-446.

8. Lavrentaki A, Paluzzi A, Wass JA, Karavitaki N (2017) Epidemiology of acromegaly: review of population studies. Pituitary 20(1): 4-9.

9. Hoskuldsdottir GT, Fjalldal SB, Sigurjonsdottir HA (2015) the incidence and prevalence of acromegaly, a nationwide study from 1955 through 2013. Pituitary 18(6): 803-807.

10. Burton T, Le Nestour E, Neary M, Ludlam WH (2016) Incidence and prevalence of acromegaly in a large US health plan database. Pituitary 19(3): 262-267.

11. Portocarrero Ortiz L, Vergara Lopez A, Vidrio Velazquez M, Uribe Diaz AM, García Dominguez A, et al. (2016) The Mexican Acromegaly Registry: Clinical and biochemical characteristics at diagnosis and therapeutic outcomes. J Clin Endocrinol Metab 101(11): 3997-4004. 
12. Rosario PW, Calsolari MR (2012) Screening for acromegaly by application of a simple questionnaire evaluating the enlargement of extremities in adult patients seen at primary health care units. Pituitary 15(2): 179183.

13. Day PF, Loto MG, Glerean M, Picasso MF, Lovazzano S, et al. (2016) Incidence and prevalence of clinically relevant pituitary adenomas: retrospective cohort study in a Health Management Organization in Buenos Aires, Argentina. Arch Endocrinol Metab 60(6): 554-561.

14. López Gavilanez E, Guerrero Franco K, Solórzano Zambrano N, Navarro Chavez M, Lopez Estrella C, et al. (2016) Epidemiology of acromegaly in Ecuador. Endocrinol Nutr 63(7): 333-338.

15. http://www. ecuadorencifras.gob.ec/censo-de-poblacion-y-vivienda

16. https://sni.gob.ec/proyecciones-y-estudios-demograficos
17. Kwon O, Song YD, Kim SY, Lee EJ (2013) nationwide survey of acromegaly in South Korea. Clin Endocrinol (Oxf) 78(4): 577-585.

18. Bex M, Abs R, T’Sjoen G, Mockel J, Velkeniers B, et al. (2007) AcroBel-the Belgian registry on acromegaly: a survey of the 'real-life' outcome in 418 acromegalic subjects. Eur J Endocrinol 157(4): 399-409.

19. Acosta Naranjo WD, Salazar Vega JL, Carrillo Rivadeneira DP (2018) Caractericas clinics in los pacientes with acromegalia atendidos in el Servicio de Endocrinología Del Hospital Eugenio Espejo, Quito, Ecuador. Revista Colombian de Endocrinología Diabetes and Metabolism 5(2): 84

20. Broder MS, Chang E, Cherepanov D, Neary MP, Ludlam WH, et al. (2016) Incidence and prevalence of acromegaly in the united states: a claimsbased analysis. Endocr Pract 22(11): 1327-1335. 